\title{
Meeting novel experimental needs with an Apple Pascal controlled interfacing system
}

\author{
DONALD M. DOUGHERTY \\ Ohio University, Athens, Ohio
}

\begin{abstract}
In this article, we describe how to combine an inexpensive interface with an independent timing card to solve some common timing and programming problems. Problems were encountered when we tried, by modifying commercial software, to create novel programs that would accurately control events in our operant conditioning chambers. The solution was to combine a Life Science Associates (LSA) Apple Interfacing System with an Applied Engineering Timemaster II H.O. timing card. Three aspects of the solution are described: (1) LSA's interfacing hardware; (2) the Timemaster II H.O. timing card; and (3) the Pascal commands necessary to access the timing card. An example, a program to control a concurrent variable-interval schedule, shows how the timing card is used in conjunction with the interface to control and monitor experiments. The system offers many advantages over earlier researcher-built approaches and provides a flexible, accurate, and inexpensive alternative to commercial systems.
\end{abstract}

Several laboratory-built interfacing systems for Apple II series computers have been offered to the readers of Behavior Research Methods, Instruments, \& Computers (Gordon, Foree, \& Eckerman, 1983; Jenkins, 1982; Rayfield, 1982; Rayfield \& Carney, 1981; Thompson, 1979). In addition, at least two commercial systems, SKED (or SUPERSKED) and OPN are available (Snapper, Kadden, \& Inglis, 1982; Spencer \& Emmett-Oglesby, 1985). These commercial systems provide the computer hardware, as well as a specifically designed programming language to control operant experiments. Yet many researchers have chosen not to build their interface systems or purchase these commercial systems. Instead, they design their own systems and write their own programs to control the interface. Carpenter (1986) found, after surveying 415 small to moderately sized psychology departments, that the Apple II series computers and compatibles made up 53\% of the computers (IBM compatibles made up $17 \%$ ) found in these departments; $60 \%$ of all respondents reported that they developed their own software for a wide range of purposes. The goal cited most often (by $56 \%$ of these researchers) consisted of the real-time control of laboratory events. This is puzzling, because many integrated systems are available that include both interfacing hardware and programming software and that are specifically designed to control experiments. Still, many researchers choose not to use these systems.

There are many possible reasons why researchers have not adopted such integrated systems. Certainly, one is their cost: Integrated systems such as SKED or SUPERSKED

The author is indebted to Paul Lewis for his critical reading of the manuscript. Correspondence and requests for reprints should be addressed to Donald M. Dougherty, Department of Psychology, Ohio University, Athens, OH 45701.
(Snapper et al., 1982) and OPN (Spencer \& EmmettOglesby, 1985) are available for a variety of computers, but they are expensive. Researchers may also lack the computer skills or time to put such an elaborate system into use. But perhaps most importantly, as Carpenter (1986) suggests, commercial software and hardware packages frequently do not meet the researcher's needs. Modifying software package systems is often difficult because they have been designed to meet specific needs; probably the biggest difficulty lies in keeping the real-time base accurate.

Many integrated systems, as well as many software package programs such as CORE, MasterFORTH, and Apple-Psych, have been described (Barnes \& Burke, 1988; Chayer-Farrell \& Freedman, 1987; Marshall-Goodell, Gormezano, Scandrett, \& Cacioppo, 1981). With perhaps the exception of Digitry's Cognitive Testing Station (CTS), none of the interfacing alternatives, at least for the Apple II series computers, has provided both a description of an inexpensive commercially available interfacing system, and a description of a programming strategy using the Pascal language to control the interface and timing system. Although Digitry's CTS does use the Pascal language to control the interface, it is more expensive than the solution that follows. Of more concern, however, is that none has adequately described a complete Apple interfacing system controlled by the Pascal language. Many researchers need a simple up-to-date interfacing system that can be controlled directly with a common computer language.

The combination of an Apple II Interfacing System (Life Science Associates, henceforth LSA; \$349) with a Timemaster II H.O. timing card (Applied Engineering; \$99) produces a complete system with advantages over earlier interfacing solutions, which suffered from several specific deficiencies. Some of them required the researcher to build much of the interfacing hardware (Jenkins, 1982; 
Rayfield, 1982; Rayfield \& Carney, 1981; Thompson, 1979); often this was a difficult, if not impossible, task for the novice, who had to spend many hours wiring and assembling the components. Today, however, commercial interfacing systems like LSA's require little assembly time and also provide more reliability and technical support for researchers; in addition, an inexpensive, yet reliable, computer interface can be purchased for approximately the cost of the components. Earlier interfacing solutions also used timing systems that were less accurate than the Timemaster II H.O. (Gordon et al., 1983; Jenkins, 1982; Rayfield, 1982; Rayfield \& Carney, 1981; Thompson, 1979). Yet probably the most important deficiency of the earlier systems is that they relied primarily on a combination of BASIC and assembly language routines (Jenkins, 1982; Rayfield, 1982; Rayfield \& Carney, 1981; Thompson, 1979); because assembly language is difficult to understand and BASIC is slow, these languages often cannot meet present-day research needs (Kaplan, 1985).

The present system resolved our fundamental problem: to create novel experimental procedures and contingencies. It was our inability to modify the commercially available software to accommodate our specific research needs that led us to the present solution. It may provide an alternative or serve as a model for other researchers. With it, researchers can write their own programs, using the Pascal language to create novel experiments. The ability to control and monitor experimental events directly through the Pascal language will also increase productivity, because more experiments can be implemented. Apple II series computers are still found in most psychology departments or, if not, they can be obtained from the large market of used Apple computers and compatibles.

Three aspects of the interfacing system are presented: (1) LSA's Apple II interfacing system; (2) the strategy that integrates the interfacing hardware with the Timemaster II H.O. to produce executable programs; and (3) a procedure that produces an executable program that integrates the interface with the timing card (a concurrent variable-interval schedule-see Ferster \& Skinner, 1957is used as an example).

\section{LSA APPLE INTERFACING SYSTEM}

The LSA Apple Interfacing System for the Apple II, II +, and Ile computers and compatibles has several important features. (Note that LSA also makes similar systems for IBM-PC and Tandy computers.) LSA's interface includes two boards connected by a ribbon cable; one board is put into Slot 5 in the computer, and the other is located externally. The external board (driven by $5-12 \mathrm{~V}$ ac or $\mathrm{dc}$ ) is equipped with 16 output terminals and 16 input terminals; each output has its own LED indicator, which signals when the output is on. The 16 input terminals on the external board allow the computer to monitor response keys. Each input terminal has its own pushbutton, which allows the programmer to simulate an input signal (e.g., a leverpress). The computer is capable of driving outputs that require less than $30 \mathrm{~mA}$, which is adequate for most psychological research equipment.

Once the interface is installed, the output and input terminals are connected to the equipment so that experiments can be monitored and controlled. The inputs are connected directly to the response levers in the chambers, to sense responses by means of the $5 \mathrm{~V}$ of ac or dc available on the interface; the inputs are activated by the 5-V signals. Connecting the outputs can be a bit more difficult. Outputs requiring less than $30 \mathrm{~V}$ and $30 \mathrm{~mA}$ can be driven directly from the interface; otherwise, the outputs can be used to operate mechanical relays (with the required current capacity) to drive equipment requiring more than $30 \mathrm{~V}$ or $30 \mathrm{~mA}$. It is possible to use solid state equipment exclusively, by adding a transistor driver board (also available from LSA); this additional board allows larger $\mathrm{dc}$ devices to be controlled directly with heavy duty transistors. The outputs are normally open circuits. Software commands are used to close circuits (to turn equipment on) and to open circuits (to turn equipment off).

\section{TIMING CARD AND INTERFACING SYSTEM}

Although LSA's software allows the timing of experimental events, modifying their software to produce novel experiments makes the time intervals inaccurate. Like others, LSA's interface provides a real-time base by using the Apple computer's internal clock. By making the necessary divisions of the computer's internal clock, the interface provides time intervals equal to $0.01602 \mathrm{sec}$ or $62.424 \mathrm{~Hz}$ (Fowler, 1985). These intervals, when counted, provide the real-time base. Unfortunately, when a program executes, some time divisions pass by without being counted.

Commercial software programmers calibrate their programs and make adjustments; real time is corrected by a predetermined amount that corrects for the error (the divisions of time that were missed and not counted). Userwritten programs may not preserve the real-time base. And it is difficult for the novice programmer to create user-written programs without severely interfering with the timing system provided with the interface. Methods needed to calibrate a user-written program are laborious and out of the reach of most programming novices. Calibration requires using a precise TTL frequency standard (such as the Global Specialties Corporation 4401 Frequency Standard). We were unable to create a user-written program that would meet our needs, and, at the same time, preserve accurate time intervals. An independent timing card solved our problems and made accurate timing possible.

The Timemaster II H.O. can be easily accessed, while the computer is operating, in the Pascal environment. This is done by means of commands that are understandable to the novice programmer; the Timemaster II H.O. provides a crystal-time base accessible to the millisecond $(32,768.00 \mathrm{~Hz})$. All the software necessary to access the 
Timemaster II H.O. from a Pascal program is provided by Applied Engineering; a new Apple Pascal system file is provided that replaces an existing system file on the Apple Pascal disk. After installing the new system file, prewritten functions may be called upon in the user's program to access the Timemaster II H.O. clock. Several increments of time can be accessed: day, month, year, hours, minutes, seconds, and milliseconds. In our application, three increments sufficed: hours, minutes, and seconds. The commands that access these are CLHOURS, CLMINUTES, and CLSECONDS, respectively. Combining these three variables provided the information necessary to control and monitor experiments. See the Listing for a concurrent variable-interval schedule provided as an example.

In particular, we combined the hours, minutes, and seconds to create a real variable called TIME to which we assign the present value of the clock each time we access it. We convert the accessed time to the total number of seconds. Below is an example of a command that we use.

TIME $:=($ CLHOURS $* 60 * 60)+($ CLMINUTES*60) $+($ CLSECONDS $)$

This is a relatively straightforward approach to timing.

Besides providing a simple and accurate way to control and monitor experiments, we have found another benefit to this system. For example, an accelerator card can be used that makes the computer execute 3.5-3.6 times faster; the Timemaster II H.O. is unaffected by the accelerator card. We use an accelerator card produced by Applied Engineering called Transwarp. The speed is helpful for writing new programs, since the Apple Pascal compiler is slow compared to Turbo Pascal and often takes several minutes. The added speed makes programming a bit more enjoyable.

\section{A PASCAL PROGRAMMING EXAMPLE}

The appended program listing provides an example of how an independent timing card can be integrated with the LSA interface to solve timing problems and save programming time. This program is designed to control two keys in an operant chamber (a concurrent schedule), each with its own variable-interval schedule (a changeover delay can also be specified in the program); it is a modifiable program that can be changed to suit experimental needs. The Listing is a condensed version of a program that we have been collecting data with for several months. Two inputs are used, one for each response key, and five outputs are used to control the houselights, whitenoise generator, grain hopper, and two keylights; each of these devices is assigned to a specific input or output. All inputs and outputs are described on the program listing, and some brief comments are included for each of the procedures.

To control experimental events requires relatively simple Pascal code. The following two instructional texts are use- ful for the Pascal leamer: TURBO Pascal: An Introduction to the Art and Science of Programming (Savitch, 1988); and I Speak Pascal to my Apple (Aubrey \& Aubrey, 1985).

\section{CONCLUSIONS}

LSA's interfacing system and the Timemaster II H.O. timing card can be combined to provide experimenters with a flexible interfacing system at a reasonable cost. The use of an independent timing card like the Timemaster II H.O. simplifies programming procedures and solves some of the timing problems that are encountered in the attempt to modify commercial software.

The interface is available from Life Science Associates, One Fenimore Road, New York 11705; the Timemaster II H.O. timing card is available from Applied Engineering, P.O. Box 5100, Carrollton, TX 75011.

Copies of the concurrent program in the Listing are available from the author either by mail (see author's note) or through Bitnet (from PLEWIS@ OUACCVMB). Several other programs, also written by the author, will be provided upon request: fixed-interval, variableinterval, fixed-ratio, variable-ratio, chaining, and autoshaping programs.

\section{REFERENCES}

AUbrey, B. J., JR., Aubrey, B. J., III. (1985). I speak Pascal to my Apple. Hasbrouck Heights, NJ: Hayden.

BARnes, S., \& Burke, R. S. (1988). What is Apple-Psych? Behavior Research Methods, Instruments, \& Computers, 20, 150-154.

CARPENTER, D. L. (1986). A survey of microcomputer use in small psychology departments. Behavior Research Methods, Instruments, \& Computers, 18, 155-156.

Chayer-Farrell, L., Freedman, N. L. (1987). CORE: Computercontrolled operant reinforcement. Behavior Research Methods, Instruments, \& Computers, 19, 319-326.

FERSTER, C. B., SKINNER, B. F. (1957). Schedules of reinforcement. New York: Appleton-Century-Crofts.

FoWLER, S. C. (1985). Apple II Pascal programs for the microanalysis of operant behavior. Bayport, NY: Life Science Associates.

Gordon, W. A., Foree, D., Eckerman, D. A. (1983). Using an Apple II microcomputer for real-time control in a behavioral laboratory. Behavior Research Methods \& Instrumentation, 15, 158-166.

JENKINS, W. M. (1982). Interfacing the Apple II for the behavioral laboratory. Behavior Research Methods \& Instrumentation, 14, 345-347.

KAPLAN, H. L. (1985). When do professional psychologists need professional programmers' tools? Behavior Research Methods, Instruments, \& Computers, 17, 546-550.

Marshall-Goodell, B., Gormezano, I., Scandrett, J., \& CACIOPPO, J. T. (1981). The microcomputer in social-psychological research: An Apple II/FIRST laboratory. Sociological Methods \& Research, 9, 502-512.

RAYFIELD, F. (1982). Experimental control and data acquisition with BASIC in the Apple computer. Behavior Research Methods \& Instrumentation, 14, 409-411.

RAYField, F., CARNEY, J. (1981). Controlling behavior experiments with BASIC on 6502-based microcomputers. Behavior Research Methods \& Instrumentation, 13, 735-740.

SAvITCH, W. J. (1988). TURBO Pascal, an introduction to the art and 
science of programming (2nd ed.). Menlo Park, CA: Benjamin/ Cummings.

Snapper, A. G., KAdden, R. M., \& Inglis, G. B. (1982). State notation of behavioral procedures. Behavior Research Methods \& Instrumentation, 14, 329-342.

Spencer, D. G., JR., \& Emmett-Oglesby, M. W. (1985). Parallel processing strategies in the application of microcomputers to the behavioral laboratory. Behavior Research Methods, Instruments, \& Computers, 17, 294-300.

THOMPSON, G. C. (1979). Behavioral programming with the APPLE II microcomputer. Behavior Research Methods \& Instrumentation, 11, 585-588.

\section{LISTING}

Concurrent Variable-Interval Program

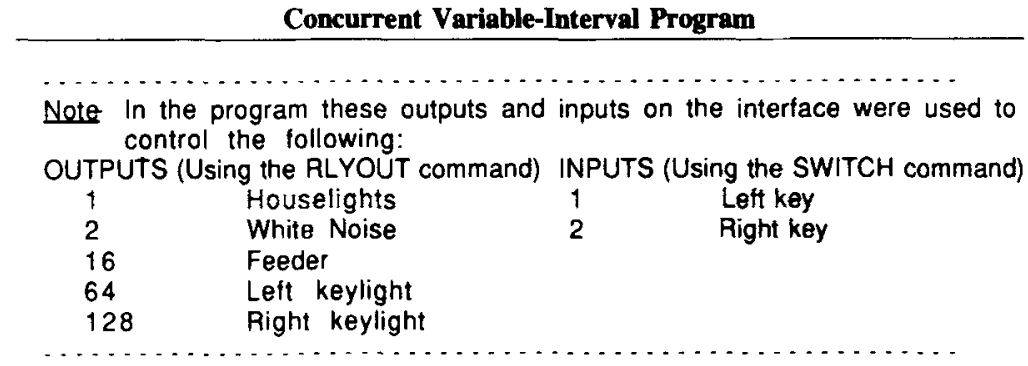

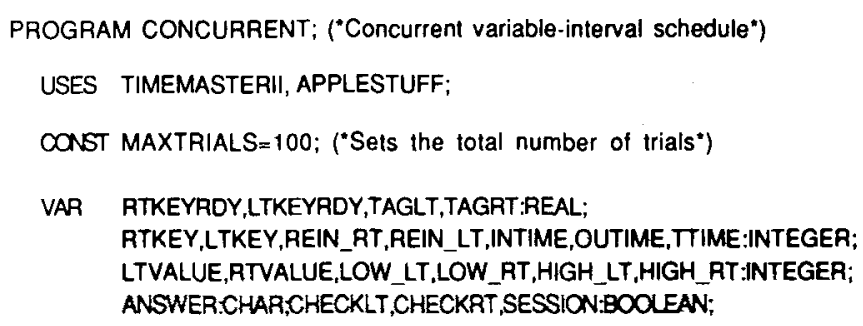


LOW_RT:=(ROUND(RTVALUE/2));LOW_LT:=(ROUND(LTVALUE/2)); END;

HIGH_RT $:=\left(3^{*}(\right.$ LOW_RT $\left.)\right) ; H I G H L L T:=\left(3^{*}(\right.$ LOW LT $\left.)\right)$

PROCEDURE MENU;("Prints menu describing variable-interval schedule choices") BEGIN

PAGE(OUTPUT);

WRITELN' CONCURRENT VARIABLE-INTERVAL SCHEDULE MENU");

WRITELN('You may choose from the available list of schedules or create'): WRITELN('your own. Select an option by entering the corresponding'): WRITELN('number.'):

WRITELN(' LEFT KEY RIGHT KEY');

WRITELN(' (1) VI $15 \quad$ VI 15'):

WRITELN(' (2) VI $30 \quad$ VI 30')

WRITELN(' (3) VI $60 \quad$ VI $\left.60^{\prime}\right)$;

WRITELN(' (4) VI $30 \quad$ VI 90')

WRITELN(' (5) MAKE A NEW SCHEDULE');

WRITELN(' Enter your choice followed by a return') READLN(ANSWER);

SETPARAMETERS;

PAGE(OUTPUT);

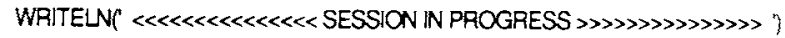
END;

PROCEDURE INITSESSION;("Initializes all variables")

VAR TIME:REAL;RANDOM_RIGHT,RANDOM LEFT:INTEGER;

BEGIN

RTKEY $:=0 ;$ LTKEY $:=0 ;$ REIN_RT $:=0 ;$ REIN LT $:=0 ;$ TAGRT $:=0 ;$ TAGLT $:=0$

CHECKRT:=FALSE:CHECKLT:=FALSE;RTKEYRDY: $=0 ;$ LTKEYRDY: $:=0$

RANDOM_RIGHT $:=0 ;$ RANDOM LLFF $:=0 ;$ INTIME $:=0 ;$ OUTIME $:=0 ;$ TTIME $:=0$;

TIME:=0;SESSION:=TRUE:

RANDOMIZE:

MENU;

RANDOM_RIGHT:=RND(LOW_RT,HIGH_RT);

RANDOM_LEFT: $=$ RND(LOW LT,HIGH_LT):

TIME: $=($ CLHOURS*60*60)+(CLMINUTES*60)+(CLSECONDS);

RTKEYRDY:=RANDOM RIGHT+TIME;LTKEYRDY:=RANDOM_LEFT+TIME: END;

INTIME: $:($ CLHOURS*60*60)+(CLMINUTES*60)+(CLSECONDS $)$

PROCEDURE PECK(VAR KEY:INTEGER;VAR TAG:REAL);

("Counts pecks and tags each peck for change-over-delay") BEGIN

KEY:=KEY $+1:\left({ }^{*}\right.$ Counts number of responses that occur")

REPEAT UNTIL (SWITCH(1)=FALSE) AND (SWITCH(2)=FALSE);

TAG: $=\left(\right.$ CLHOURS*60*60) $+\left(\right.$ CLMINUTES $\left.{ }^{*} 60\right)+($ CLSECONDS $)$ END;

PROCEDURE REINFORCE;('Operates the reinforcement device for four seconds')

VAR TIME:REAL;RANDOM_RIGHT,RANDOM_LEFT:INTEGER;

PROCEDURE SUBREINFORCE(VAR NUMREIN:INTEGER);

VAR EXITTIME:REAL:REIN:INTEGER;

BEGIN ("SUBREINFORCE")

REIN : $=4 ;($ "Number of seconds for feeder operation*)

EXITTIME: $=\left(\right.$ CLHOURS $\left.{ }^{*} 60^{*} 60\right)+($ CLMINUTES*60) $+($ CLSECONDS $)+R E I N$ BEGIN

RLYOUT(1,FALSE);RLYOUT(128,FALSE);RLYOUT(64,FALSE);

REPEAT RLYOUT(16,TRUE)

UNTIL EXITTIME $<=\left(\right.$ CLHOURS $\left.{ }^{*} 60^{*} 60\right)+($ CLMINUTES*60) $+($ CLSECONDS $) ;$

NUMREIN:=NUMREIN+1

END

END;("SUBREINFORCE")

BEGIN ("REINFORCE")("Determines change-over-delay")

IF CHECKRT=TRUE THEN

BEGIN

TAGRT: $=($ CLHOURS*60*60)+(CLMINUTES*60)+(CLSECONDS):

IF ABS(TAGRT-TAGLT) > 3 THEN SUBREINFORCE(REIN RT): 


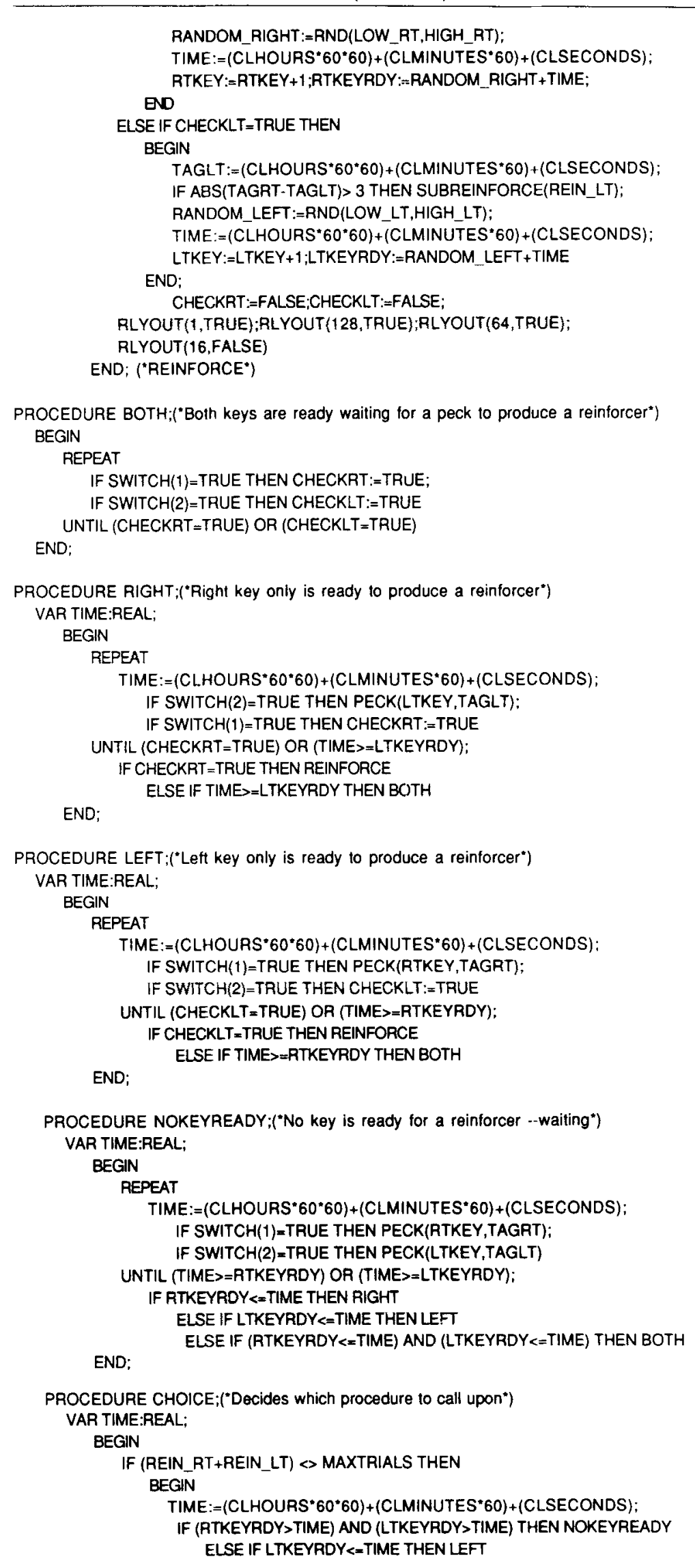


LISTING (Continued)

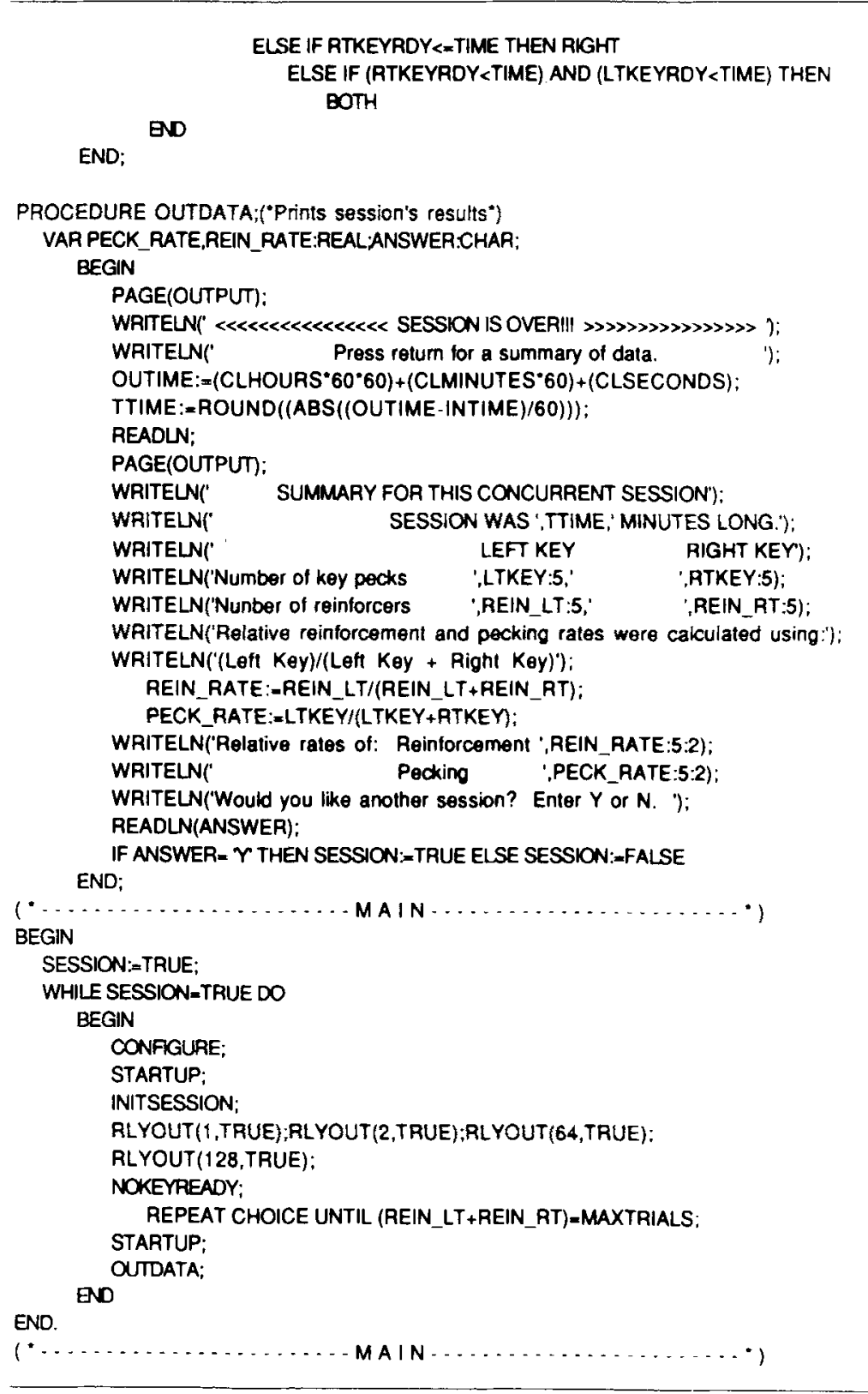

(Manuscript received April 16, 1990;

revision accepted for publication October 1, 1990.) 